mical to keep the prepared fibrin by drying it in a current of air than to preserve it under ether, as usually recommended.

September 27

Note on Actinometry by Oxalic Acid

Oxalic acid is entirely oxidised by light (Proc. Roy. Soc. No. I9I, and Chemical Nezes, October 8, I880), and affords, by reason of its own physical properties and those of the products of the reaction, an excellent medium for actinometry. A preliminary series of experiments on the physical conditions which modify this oxidation show that, c.p., the effect is greater in direct proportion to the extent of exposed surface of the solution but inversely as its depth. It is greater also in proportion to the strength of the solution; and it would appear-I speak for the present quite provisionally - that in this relation the reaction follows a definite law, being as the square root of the mass.

September 27 Arthur Downes

\section{Humming in the Air caused by Insects}

IN a letter to the Hon. Daines Barrington (letter lxxx.) the Rev. Gilbert White, the well-known author of the "Natura History of Selborne," mentions a strange humming sound in the air. He writes:- "There is a natural occurrence to be met with upon the highest parts of our downs in hot summer days which always amuses me much without giving me any satisfaction with respect to the cause of it : and that is a loud audible humming as of bees in the air, though not one insect is to be seen. This sound is to be heard distinctly the whole common through from the Money Dells to my avenue gate. Any person would suppose that a large swarm of bees was in motion, and playing about over his head. This noise was heard last week on June 28."

It is singular that no explanation has been offered by any one for such a common phenomenon. I am convinced that the humming sound mentioned by Gilbert White was nothing more than the noise occasioned by the vibrations of millions of insects' wings in the air. In hot summer evenings in particular I have heard these peculiar humming sounds, and know them to be caused by immense hordes of gnats and midges which fill the air with their numbers. W. HARCOURT BATH

The Limes, Sutton Coldfield, near Birmingham, October

\section{Mimicry in Snakes}

A CURIOUs fact has been lately brought to my notice by a friend of mine, Mr. H. M. Oakley, in connection with the Dasypeltis scaber, Linn., or egg-eating snake-the "Eijer eter" of the Dutch colonists-which, if not already well known, may prove of interest to some of your readers. The specimen obtained by Mr. Oakley was caught at Hout Bay some twenty miles from Cape Town, and is about 3 feet in length, and its size, markings, and colour bear sufficient resemblance to those of the Berg Adder (Clothos atropos, Linn.) to be easily mistaken for that snake. It also has keeled scales, generally characteristic, at the Cape, of venomous species. Its head has, however, the long lacertine shape distinctive, here, of harmless snakes, but, when aroused and alarmed or irritated, it flattens it out until it assumes the usual viperine shape of the "club" in a playing card. It then coils as for a spring, erects its head with every appearance of anger, produces a hissing noise with its scales, not unlike the hiss of a puff adder or cobra, and darts forward as if to strike its fangs into its foe, and in every way exactly simulates the motions of an irritated berg adder. This snake has, however, neither fangs nor teeth (which, indeed, would not be required for egg-swallowing), and is not poisonous, a fact which was placed beyond doubt by Mr. Oakley repeatedly placing his finger in the reptile's mouth. This seems a clear instance of mimicry of another species for defensive purposes, but I am not aware of another instance among ophidians.

\section{W. HAMMOND TOOKE}

Cape Town, Cape of Good Hope, September 8

\section{THE COLONIAL AND INDIAN EXHIBITION}

CONTINUING our review of the most noteworthy or interesting vegetable products now being exhibited at South Kensington, we find in close contiguity to those from British Guiana, described in NATURE, July I 5 , p. 242, the exhibits from
Mauritius.-The entire collection, though not large, is one of some interest, and the vegetable kingdom plays by far the most important part in the exhibits. The collection of fibres will attract attention as much for its completeness as for the care with which they have been prepared. Many are of scientific interest only, being obtained from plants that could never be turned to commercial account, such, for instance, as Hyophorbe Verschaffeltii, Latania commersonii, Lodoicea sechellarum, Macrozamia spiralis, \&c. This collection is exhibited by the Botanical Gardens, as is also a collection of woods of similar interest. Some notes on these woods are useful. Thus, we are told that Tecoma pentaphylla has a soft white wood, not much used, and that it is a moderate-sized shade-tree of rapid growth. Samples of the wood, however, grown in the West Indies, show a close and even grain, and are fairly hard-so hard, indeed, as to suggest its suitability for wood-engraving, for which purpose it has been tried in this country, and though not by any means equal to boxwood, was reported upon as likely to be found useful for some kinds of work. The soft wood of Ficus mauritiana is used in the colony both for firewood and for hollowing out for canoes, while the hard wood of the Ebony (Diospyros Ebenum), which is described as being either black or sometimes streaked with yellow and brown, is used for inlaying, furniture, and ornamental turnery. The Bois Maigre (Nuxia verticillata) is said to produce a shortgrained timber which decomposes rapidly, but when young it makes excellent walking-sticks, which are much sought for. Terminalia Benzoin, a large tree, which has become scarce in Mauritius, produces a wood valued for many purposes. It would seem that the wood is sometimes fragrant, for it is said that "some parts of the tree were once much burnt in Mauritius as an incense." Another odoriferous wood is Noronhia Broomieana, called here Bois Sandal. The Carambnle (Averrhoa Carambola), valued in India for the sake of its acid fruits, is planted in Mauritius for the same purpose, the fruits being eaten either raw or made into tarts.

Probably the exhibits that attract most attention in the Mauritius Court are the fine samples of vanilla pods, covered as they are with an abundant coating of crystals, and shedding forth, even through the glass cases which cover them, the delicate fragrance for which vanilla is celebrated.

Seychelles.-Amongst these exhibits the Double CocoaNut, or Cocoa de Mer (Lodoicea sechellarum) is the most prominent. The double form of the fruit, which is its normal condition, is well shown, as well as a triple-lobed nut, which is not very uncommon. Here also are fine samples of vanilla, nearly, if not quite, equal to those from Mauritius. Dried papaw juice and some remarkably good specimens of essential oils are shown, all of which are extremely creditable to the colony.

Cyprus.-The vegetable products shown in this Court are not numerous, nor is there anything of novelty excepting perhaps a peculiar black substance described as honey, from the Carob or Locust Bean (Ceratonia Siliqua). The pods themselves are also exhibited, and their production, it seems, has greatly increased in recent years, stimulated by an increasing demand, especially in this country, where they are used very largely in making the patent compound cattle-foods, in consequence of their saccharine and nutritious character. Low freights have much encouraged the trade in carobs, enabling shippers to sell them at moderate prices. The quantity of carobs exported from Cyprus in 1884 amounted to 30,000 tons, about one-half of which came to England. The finest quality is produced in Limassol and Lefcara, and obtain relatively higher prices than those of Kyrenia. The average price realised for these pods is about $3 l$. per ton.

Another product of great importance to Cyprus up to 